\title{
A Novel Inverse Dynamic Model for a Magnetorheological Damper based on Network Inversion
}

Journal of Vibration and Control

$X X(X): 2-21$

(c) The Author(s) 2017

Reprints and permission:

sagepub.co.uk/journalsPermissions.nav

DOI: $10.1177 /$ ToBeAssigned

www.sagepub.com/

\section{M.J.L. Boada ${ }^{1}$, B.L. Boada ${ }^{1}$ and V. Diaz ${ }^{1}$}

\begin{abstract}
Semi-active suspensions based on magnetorheological (MR) dampers are receiving significant attention specially for control of vibration isolation systems. The nonlinear hysteretic behaviour of MR dampers can cause serious problems in controlled systems such as instability and loss of robustness. Most of the developed controllers determine the desired damping forces which should be produced by the MR damper. Nevertheless, the MR damper behaviour can only be controlled in terms of the applied current (or voltage). In addition to this, it is necessary to develop an adequate inverse dynamic model in order to calculate the command current (or voltage) for the MR damper to generate the desired forces as close as possible to the optimal ones. Due to MR dampers are highly nonlinear devices, the inverse dynamics model is difficult to obtain. In this paper, a novel inverse MR damper model based on a network inversion to estimate the necessary current (or voltage) such as the desired force is exerted by the MR damper is presented. The proposed inverse model is validated carrying out experimental tests. In addition, a comparison of simulated tests with other damper controllers is also presented. Results show the effectiveness of the network inversion for inverse modeling of an MR damper, so that the proposed inverse model can act as a damper controller to generate the command current (or voltage) to track the desired damping force.
\end{abstract}

\section{Keywords}

Magnetorheological (MR) damper, semi-active damper, inverse model, neural networks, network inversion 


\section{Introduction}

In last decades, magnetorheological (MR) dampers have gained special interest in applications of vibration isolation of civil engineering, mechanical structures and suspension systems Phu et al. (2016), El-Khoury et al. (2016), Ali and Ramaswamy (2009) and Wang and Song (2012). An MR damper is a semi-active device that contains a hydraulic fluid whose viscosity is controllable upon the application of an external magnetization field. MR dampers contain suspensions of micron-size and magnetizable particles in an oil-based fluid. In the presence of magnetic fields, these fluid particles become aligned with the field, dramatically increasing the fluid viscosity an effective damping. Along with their variable damping force, MR dampers have been shown to have very low response times, fault-safe and low power-consumption Dyke et al. (1996). Nevertheless, MR dampers are highly nonlinear devices whose dynamics are characterized by a hysteretic force-velocity response which is not mathematically easy to model. Hysteresis can cause serious problems in controlled systems such as instability and loss of robustness. There exists a rich literature of direct models which attempt predict the damping force of an MR damper and explain its hysteretic behavior. MR damper models can be classified into two categories depending on the way the model is obtained: parametric and non-parametric. Parametric models are most desirable, because the parameters in the model have some physical meaning Choi and Han (2005), Gamota and Filisko (1991), Stanway et al. (1987) and Wereley et al. (1998). Nevertheless, the main drawback of these techniques is that to obtain each of these parameters, the corresponding damping force must be measurable, and an adequate phenomenological form of the model must be selected. This often requires high computational effort. An alternative to parametric models is non-parametric ones which are able to model response behavior accurately with considerable flexibility without the necessity that their parameters have physical meaning. Most of these models are based on neural networks Boada et al. (2011), Du et al. (2006), Smyth et al. (2002) and polynomial curve-fitting Li et al. (2013), Metered et al. (2015).

Most of the developed controllers determine the desired damping forces which should be produced by the MR damper. Nevertheless, the force exerted by the MR damper cannot be commanded directly, the MR damper behaviour can only be controlled in terms of the applied current (or voltage) Zareh et al. (2014) and Zapateiro et al. (2012). In addition to this, it is necessary to develop an adequate inverse dynamic model (also

\footnotetext{
${ }^{1}$ Mechanical Engineering Department, Research Institute of Vehicle Safety (ISVA), University of Carlos III de Madrid, Spain
}

\section{Corresponding author:}

Maria Jesus L. Boada, Mechanical Engineering Department, Research Institute of Vehicle Safety (ISVA), University of Carlos III de Madrid, Avda. de la Universidad, 30, 28911, Leganes, Madrid, Spain.

Email:mjboada@ing.uc3m.es 
called as damper controller) in order to calculate the command current (or voltage) for the MR damper to generate the desired forces as close as possible to the optimal ones.

Due to the nonlinear characteristic of the MR dampers, its inverse dynamic model is difficult to obtain. Some inverse dynamic models for MR dampers have been proposed. Tsang et al. (2006) propose a simplified inverse dynamic model for both the Bingham plasticity and the Bouc-Wen hysteresis models in order to calculate the optimal fluid yield stress or input current. The effectiveness of the proposed model has been demonstrated through numerical simulations. Nevertheless, the inverse models based on parametric models need a priori knowledge of the nonlinear dynamics between variables due to the coefficients of these models have a physical meaning. Choi et al. (2001)

propose a polynomial model, which can easily calculate the input current with measurable velocity. The effectiveness of the proposed model was also shown by comparing the measured results with the predicted ones at various operating conditions.

A main drawback of the polynomial models is that they requires many parameters to predict the necessary current (or voltage) in order to generate the required control force (Tudon-Martinez et al.(2015)). Neural networks (NN) have been effectively applied to model complex systems due to their good learning capability. Zong et al. (2012) propose an adaptive neuro-fuzzy inference system (ANFIS) inverse model to determine the input current so as to gain the desired damping force. Simulation results demonstrate that the

desired force can be accurately tracked using the ANFIS technique. Wang and Liao (2005), Metered et al.(2010), Xia (2003) and Chang and Zhou (2002) propose an inverse dynamic MR damper model based on recurrent neural networks (RNN). In this type of $\mathrm{NN}$ model, the modeling of forward dynamics is carried out adding time delays in the input vector. However, this type of NN increases the architecture size and the instrumentation cost of the control system. In addition, modeling of the forward dynamics using recurrent $\mathrm{NN}$ requires two or more time delays of each input increasing the computing time (Tudon-Martinez et al.(2012), Tudon-Martinez et al. (2015) and Ekkachai et al. (2013)). For this reason, it is necessary to propose new inverse models which provide good performance with a simpler architecture.

Inverse MR damper modeling can be considered as a problem to obtain an inverse solution i.e. to estimate the cause (command current) from the result (desired force), or derive the rule from the cause and result. As opposed to direct problem, the wellposedness of the inverse problem, i.e. the uniqueness of the solution, is not always guaranteed (Ogawa et al. (1998)).

Network inversion has been proposed as a method for solving practical inverse problems such as the image reconstruction problem (Linden and Kindermann (1989)), the inverse kinematics of a robot arm (Ogawa and Kanada (2010)) and so on (Owaga (2009), Ogawa (2016), Jensen et al. (1999)) and its effectiveness has been shown. In this paper, a novel inverse MR damper model based on modified network inversion to estimate the necessary current such as the desired force is exerted by the MR damper is proposed.

The paper is structured as follows. In Section 2 the inverse dynamic MR damper model based on network inversion is presented. Then, in Section 3, the details of the 


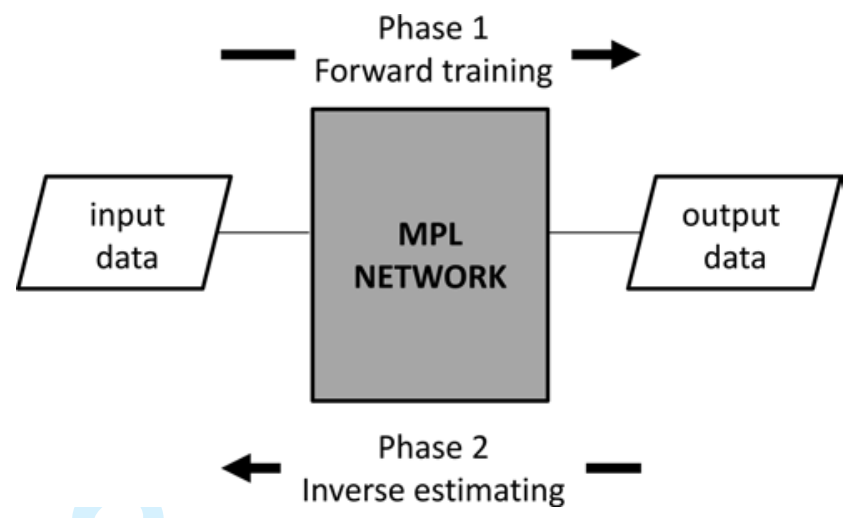

Figure 1. Network inversion procedure.

experimental setup used during this work are discussed. In Section 4, results obtained are shown and discussed. Finally, conclusions are presented in Section 5.

\section{Proposed Inverse Dynamic Model by Network Inversion}

The inversion of the neural network allows to find a set of input patterns to produce a target output pattern (Saad and Wunsch (2007)). One of the first methods of network inversion was proposed by Linden and Kindermann (1989). In this method, inverse problem is solved by an iterative algorithm for inverting a trained multilayer neural network. The network inversion method involves two phases as is depicted in Figure 1. In the former, called forward training phase, the neural network is trained for adjusting the weight values so that is approximated the forward mapping. In the latter, called inverse estimation phase, the input of the neural network is updated for a pre-determined output value and for the weights previously obtained in the forward training phase.

As oppose to the original method where the neural network has to estimate the inputs which correspond to a given output, in the proposed inverse dynamic MR damper model only one input, the current, has to be estimated. Figure 2 shows the modified method for modeling the inverse dynamic of an MR damper.

\section{Phase 1. Forward Training}

In the forward training phase, a multilayer perceptron (MLP) neural network learns the forward dynamics of the MR damper to model its nonlinear and hysteretic behaviour:

$$
y=g(w, x)
$$

where $x$ is the input vector, $y$ is the output vector and $g$ is the translation defined by the interlayer weights, $w$, of the network. In the forward MR damper models, the inputs are usually the piston displacement, velocity or acceleration, or any combination of them, and the applied current. The output is always the force exerted by the MR damper (Bhowmik 


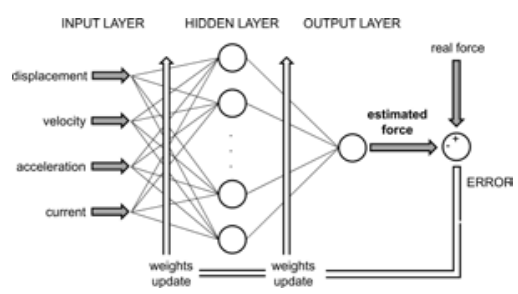

(a) Phase 1. Forward training

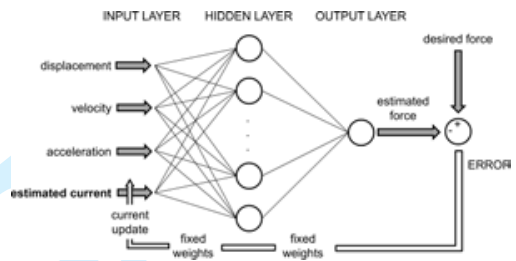

(b) Phase 2. Inverse estimation

Figure 2. Network inversion method.

(2011)). The selected inputs in the proposed model are the piston displacement, the velocity, the acceleration and the applied current. Figure 2(a) shows the architecture of the network used. The network has a single hidden layer with 30 neurons. The LevenbergMarquardt Backpropagation algorithm is used to learn the weights of the MLP neural network looking for the minimum value of the error. The network training was performed using the Matlab function trainlm.

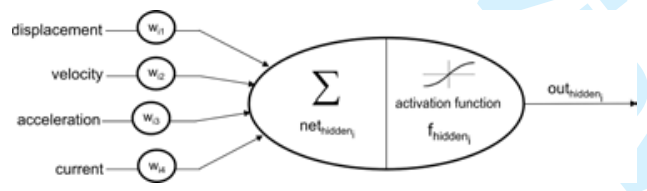

(a) i-th hidden layer neuron

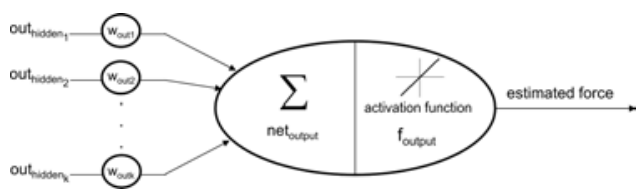

(b) output layer neuron

Figure 3. Neuron module. 


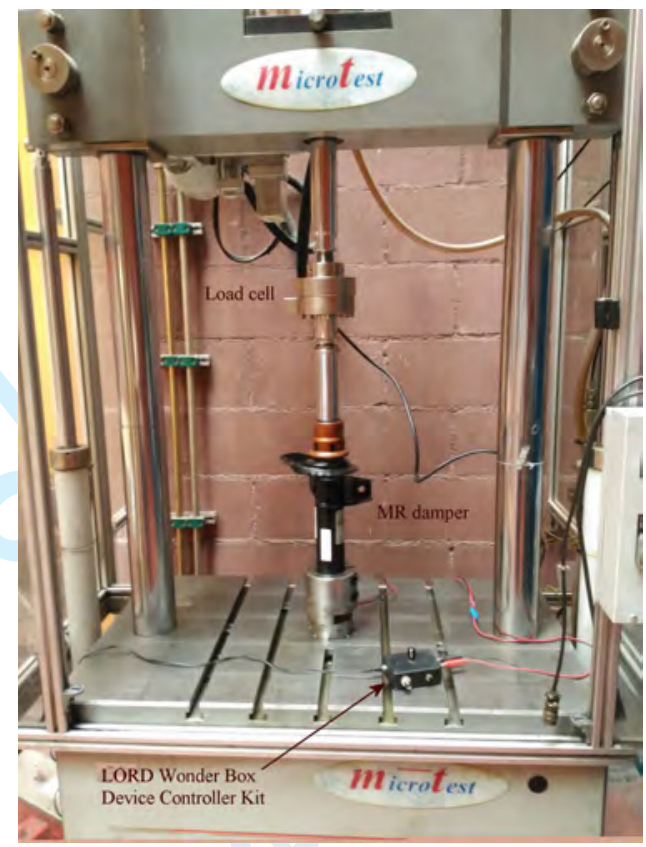

Figure 4. MR damper test machine.

\section{Phase 2. Inverse Estimation}

In the inverse estimation phase, the input (applied current) is corrected to minimize the

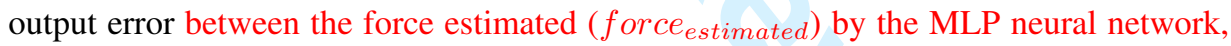
previously trained in the phase 1, and the desired control force ( force $\left._{\text {real }}\right)$. (Figure 2(b)). By fixing the weights obtained in the forward training phase, the randomly initialized applied current is iteratively updated from the provided remaining inputs (displacement, velocity and acceleration) and output (desired force), based on the gradient method:

$$
\text { current }(t+1)=\text { current }(t)-\alpha_{\text {inverse }} \cdot \frac{\partial E}{\partial \text { current }}
$$

where $\alpha_{\text {inverse }}$ is the learning rate and $E$ is the error defined as (Figure 2):

$$
E=\frac{1}{2}\left(\text { force }_{\text {real }}-\text { force }_{\text {estimated }}\right)^{2}
$$

Considering $E$ as a function of the inputs of all neurons receiving input from the input current, the partial derivative of the error with respect to this input is calculated using the chain rule:

$$
\begin{aligned}
& \frac{\partial E}{\partial c u r r e n t}=\frac{\partial E\left(\text { net }_{\text {hidden }_{1}}, \ldots, \text { net }_{\text {hidden }_{k}}\right)}{\partial \text { current }} \\
& =\sum_{i=1}^{k} \frac{\partial E}{\text { dnet }_{\text {hidden }_{i}}} \cdot \frac{\text { onet }_{\text {hidden }_{i}}}{\text { deurrent }}
\end{aligned}
$$




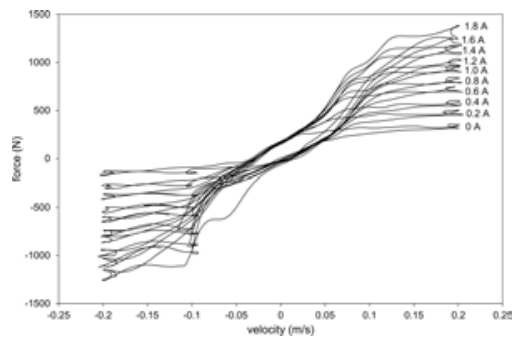

(a)

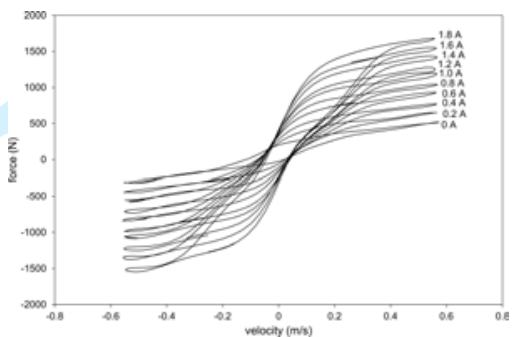

(b)

Figure 5. Experimental MR damper curves for an amplitude of the piston displacement of 15 $\mathrm{mm}$ and different levels of applied current at a frequency of excitation of: a) $2 \mathrm{~Hz}$ and b) $6 \mathrm{~Hz}$

where net $_{\text {hidden }_{i}}$ is the weighted sum of the inputs of the network in the $i t h$ hidden layer neuron. The weighted sum forms the input to the activation function $f_{\text {hidden }_{i}}$. Here, a hyperbolic tangent sigmoid function is used:

$$
f_{\text {hidden }_{i}}(z)=\frac{2}{1+e^{-2 z}}-1
$$

For one neuron in the hidden layer:

$$
\frac{\partial E}{\partial \text { net }_{\text {hidden }_{i}}}=\frac{\partial E}{\partial o_{\text {hidden }_{i}}} \cdot \frac{\partial_{\text {hidden }_{i}}}{\partial \text { net }_{\text {hidden }_{i}}}
$$

where $o_{\text {hidden }}$ is the output of the $i t h$ hidden layer neuron that is calculated as follows (Figure 3(a)):

$$
\text { ohidden }_{i}=f_{\text {hidden }_{i}}\left(\text { net }_{\text {hidden }_{i}}\right)
$$

Partial derivatives are obtained from the following equations:

$$
\begin{aligned}
& \frac{\text { dnet }_{\text {hidden }}}{\text { dcurrent }}=w_{i 4} \\
& \frac{\text { oo }_{\text {hidden }_{i}}}{{\text { } \text { net }_{\text {hidden }_{i}}}_{\text {of }}}=\left(1-o_{\text {hidden }_{i}}^{2}\right)
\end{aligned}
$$




$$
\begin{aligned}
& \frac{\partial E}{\partial o_{\text {hidden }_{i}}}=\frac{\partial E\left(\text { net }_{\text {output }}\right)}{\partial o_{\text {hidden }_{i}}} \\
& =\frac{\partial E}{\partial \text { net }_{\text {output }}} \cdot \frac{\text { nnet }_{\text {output }}}{{\partial o_{\text {hidden }_{i}}}} \\
& =\frac{\partial E}{\partial \text { force }_{\text {estimated }}} \cdot \frac{\text { fforce }_{\text {estimated }}}{\text { dnet }_{\text {output }}} \\
& \cdot \frac{\text { nnet }_{\text {output }}}{\text { ohidden }_{i}}
\end{aligned}
$$

where $w_{i 4}$ is the weight from the input current to the $i t h$ hidden layer neuron and net $_{\text {outpt }}$ is the weighted sum of the outputs of the hidden layer in the output layer neuron as is depicted in Figure 3(b). The activation function of the output layer neuron, $f_{\text {output }}$ is assumed to be linear, so that:

$$
\begin{gathered}
\frac{\partial E}{\partial \text { force }_{\text {estimated }}}=\left(\text { force }_{\text {estimated }}-\text { force }_{\text {real }}\right) \\
\frac{\partial \text { force }_{\text {estimated }}}{\partial \text { net }_{\text {output }}}=1 \\
\frac{\text { net }_{\text {output }}}{\text { oo }_{\text {hidden }}}=w_{\text {outi }}
\end{gathered}
$$

where $w_{\text {outi }}$ is the weight from the $i t h$ hidden layer neuron to the output layer neuron as is depicted in Figure 3(b).

Put it all together, the error signal to the input current is calculated by:

$$
\begin{array}{r}
\frac{\partial E}{\partial \text { current }}=\left(\text { force }_{\text {estimated }}-\text { force }_{\text {real }}\right) \\
\cdot \sum_{i=1}^{k}\left(w_{i 4}\left(1-o_{\text {hidden }_{i}}^{2}\right) w_{\text {outi }}\right)
\end{array}
$$

\section{Experimental Results}

\section{Experimental Setup}

In order to validate the proposed inverse dynamic MR model based on network inversion, a collection of experimental data were obtained for a commercial MR damper. The common way to determine the MR damper behaviour is to excite it with a sinusoidal displacement in several test cases with different frequencies of excitation, piston displacements and applied currents Kwok et al. (2007) and Xiaomin et al. (2009). Experimental data are obtained from our laboratory with a damper test machine shown in Figure 4. In the test machine, a hydraulic actuator is employed to drive the MR damper from sinusoidal displacement cycles with amplitudes of 10,15 and $20 \mathrm{~mm}$ in the $2-6 \mathrm{~Hz}$ frequency range and under the application of a set of magnetizing currents (0-1.8 A). The experimental data set are shown in Table 1. 


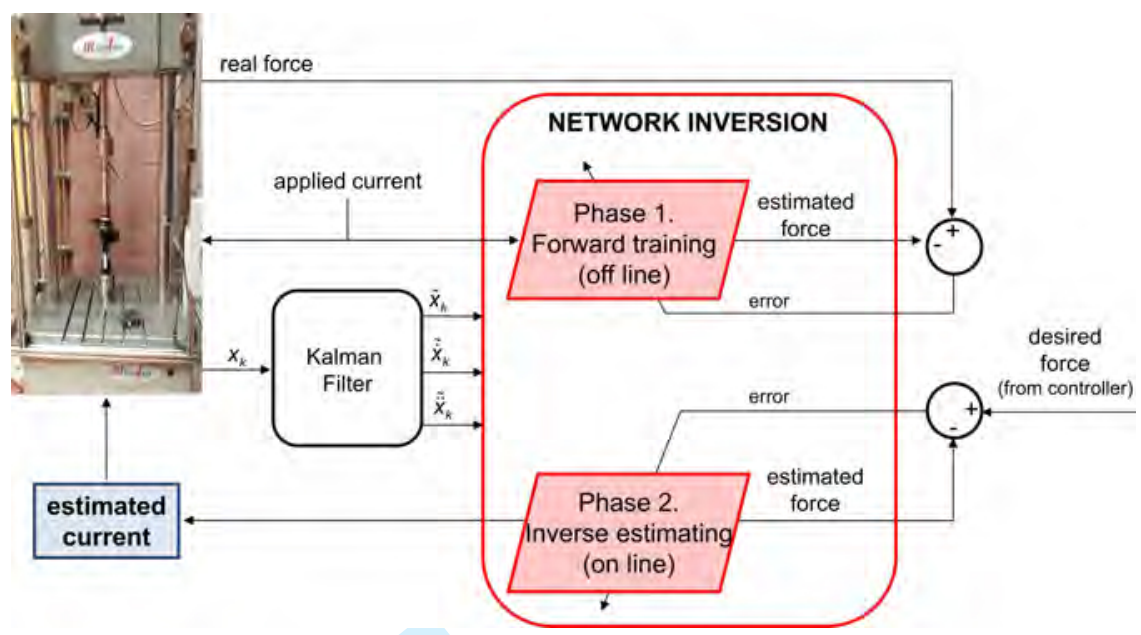

Figure 6. Scheme of the inverse modeling for an MR damper with the proposed method (network inversion).

Table 1. Experimental data set

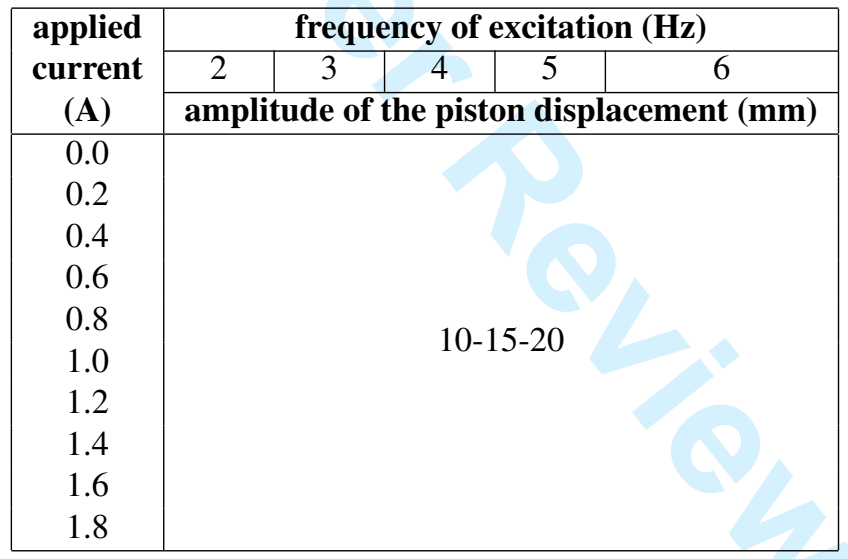

The damper stroke was positioned at its center before the test was carried out to avoid the extreme positions of the damper stroke. The damper test machine is equipped with a displacement sensor to measure the displacement $x$ of the MR damper piston and a load cell to measure the output force. The signals $x$ and force are sampled at the rate 0.5 $\mathrm{kHz}$. Figure 5 shows a series of typical response curves for the MR damper for the tests corresponding to an amplitude of the piston displacement of $15 \mathrm{~mm}$ and frequencies of excitation of 2 and $6 \mathrm{~Hz}$, respectively. As observed, in the range of small velocities the force variation displays an important hysteretic behavior, while for large velocities the force varies almost linearly with the velocity. These two distinct rheological regions over 
which dampers operate are known as the pre-yield and the post-yield regions Giuclea et al. (2004). As the current increases, the force required to yield the fluid increases and produces behavior associated with a plastic material in parallel with a viscous damper. Note that the non-zero mean force produced by the MR damper is due to the accumulator. Experimental results shows the variability of the MR damper response not only with the applied current but also with the frequency of excitation and amplitude of the piston displacement. In order to estimate the applied current from the inverse dynamic model, it is necessary to know not only the displacement of the MR damper piston, but also the velocity and acceleration. Although there are some prototypes for an integrated relative velocity sensor Nehl et al. (1995), at present, the best option it is to estimate both variables.

\section{Damper velocity and acceleration estimation from sampled position data by Kalman filter}

The simplest solution to estimate the velocity and acceleration of the MR damper piston from sampled position data is to use the finite difference (FD) method. The velocities and accelerations are calculated through the following expressions Belanger (1992):

$$
\begin{gathered}
\dot{x}_{k}=\frac{x_{k}-x_{k-1}}{T} \\
\ddot{x}_{k}=\frac{x_{k}-2 x_{k-1}+x_{k-2}}{T^{2}}
\end{gathered}
$$

Then, the results are filtered using a low-pass filter. The main problem is that this method does not achieve suitable results. The Kalman filter has been shown to be an adequate candidate to estimate the velocity an acceleration from position data Puglisi et al. (2015). This filter is a mathematical tool that is used for stochastic estimation from noisy sensor measurements. The nonlinear system governed by the nonlinear stochastic difference equations can be written as:

$$
\begin{gathered}
\mathbf{x}_{k+1}=f_{k}\left(\mathbf{x}_{k}, \mathbf{u}\right)+\mathbf{w}_{k} \\
\mathbf{y}_{k}=h_{k}\left(\mathbf{x}_{k}, \mathbf{u}\right)+\mathbf{v}_{k}
\end{gathered}
$$

where $\mathbf{x}_{k}$ is the state vector, $\mathbf{u}$ is the input vector, $\mathbf{w}_{k}$ is the process noise vector, $\mathbf{y}_{k}$ is the measurement vector and $\mathbf{v}_{k}$ is the measurement noise vector. $\mathbf{w}_{k}$ and $\mathbf{v}_{k}$ are assumed to be white, zero mean and uncorrelated:

$$
\begin{aligned}
\mathbf{w}_{k} & \sim N\left(0, \mathbf{Q}_{k}\right) \\
\mathbf{v}_{k} & \sim N\left(0, \mathbf{R}_{k}\right)
\end{aligned}
$$

where $\mathbf{Q}$ and $\mathbf{R}$ are the covariance matrices describing the second-order properties of the state and measurement noise. For the particular case of velocity and acceleration estimation from displacement data, the discrete-time system can be written as Puglisi 
et al. (2015):

$$
\begin{gathered}
{\left[\begin{array}{c}
x_{k+1} \\
\dot{x}_{k+1} \\
\ddot{x}_{k+1}
\end{array}\right]=\left[\begin{array}{ccc}
1 & T & T^{2} / 2 \\
0 & 1 & T \\
0 & 0 & 1
\end{array}\right]\left[\begin{array}{l}
x_{k} \\
\dot{x}_{k} \\
\ddot{x}_{k}
\end{array}\right]+\left[\begin{array}{c}
T^{3} / 6 \\
T^{2} / 2 \\
T
\end{array}\right]} \\
y_{k}=x_{k}+v_{k}
\end{gathered}
$$

where $T$ is the sample time period and the covariance matrices are:

$$
\begin{gathered}
\mathbf{Q}=200\left[\begin{array}{ccc}
T^{5} / 20 & T^{4} / 8 & T^{3} / 6 \\
T^{4} / 8 & T^{3} / 6 & T^{2} / 2 \\
T^{3} / 6 & T^{2} / 2 & T
\end{array}\right] \\
R=\frac{0.1^{2}}{1+\dot{x}_{k}}
\end{gathered}
$$

The Kalman filter is summarized as the following recursive equations:

1. The prediction of the state given by:

$$
\tilde{\mathbf{x}}_{k \mid k-1}=\mathbf{A} \tilde{\mathbf{x}}_{k-1 \mid k-1}+\mathbf{B} \mathbf{u}_{k}
$$

2. The predicted error covariance is computed as:

$$
\mathbf{P}_{k \mid k-1}=\mathbf{A} \mathbf{P}_{k-1 \mid k-1} \mathbf{A}^{T}+\mathbf{Q}
$$

3. The Kalman gain is calculated by:

$$
\mathbf{K}_{x}=\mathbf{P}_{k \mid k-1}+\mathbf{H}^{T}\left(\mathbf{H} \mathbf{P}_{k \mid k-1} \mathbf{H}^{T}+\mathbf{R}\right)^{-1}
$$

4. The state estimation is updated with measurement $\mathbf{y}_{k}$ :

$$
\tilde{\mathbf{x}}_{k \mid k}=\tilde{\mathbf{x}}_{k \mid k-1}+\mathbf{K}_{x}\left(\mathbf{y}_{k}-\mathbf{H} \tilde{\mathbf{x}}_{k \mid k-1}\right)
$$

5. Finally, the error covariance is updated:

$$
\mathbf{P}_{k \mid k}=\left(\mathbf{I}-\mathbf{K}_{x} \mathbf{H}\right) \mathbf{P}_{k \mid k-1}
$$

\section{Results and Discussion}

The proposed inverse model of an MR damper based on network inversion method is depicted in Figure 6. The network parameters are shown in Table 2. 12771 data are used to train the network. Other different 1419 data are used to validate the proposed model. The validation data have been taken randomly from the total of experimental data obtained. The code has been entirely written in Matlab. In the forward training phase, 


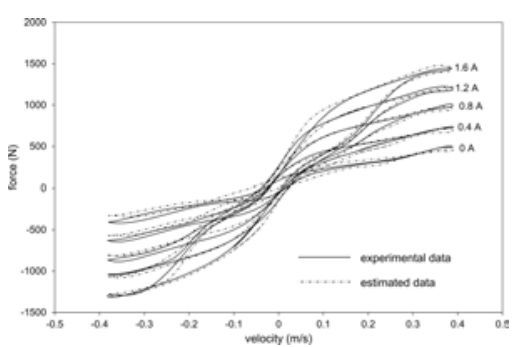

(a)

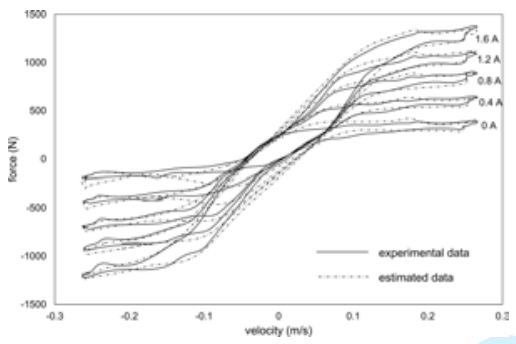

(c)

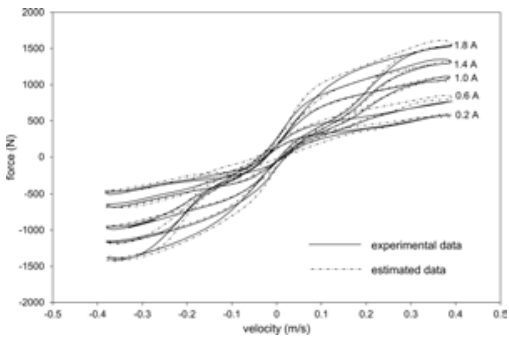

(b)

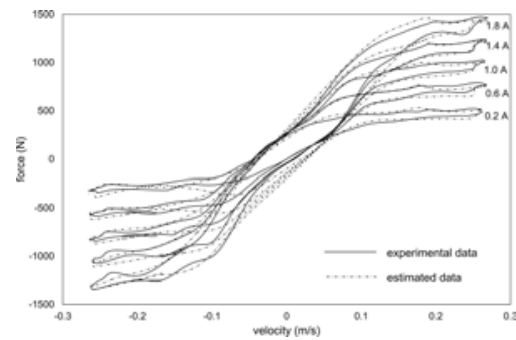

(d)

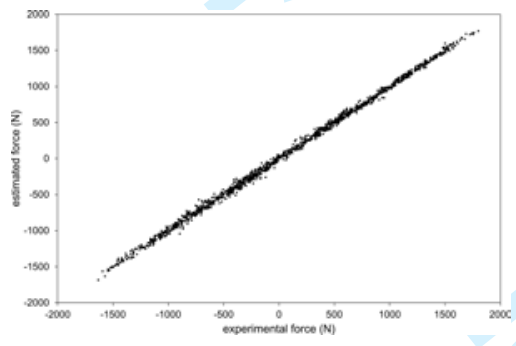

(e)

Figure 7. Comparison between experimental (solid line) and estimated (dashed line) responses obtained in the forward training phase for: a) and b) amplitude of a piston displacement of $10 \mathrm{~mm}$ and frequency of excitation of $6 \mathrm{~Hz}, \mathrm{c}$ ) and d) amplitude of $20 \mathrm{~mm}$ and frequency of excitation of $2 \mathrm{~Hz}$, and e) validation data set.

the MLP neural network learns the forward relation between the inputs (displacement, velocity, acceleration and applied current) and the output (force). Figure 7 compares the force obtained by experimental test with those estimated by the proposed model based on network inversion for different amplitudes and frequencies of excitation and for validation data set. The examination of the figure reveals that the MLP neural network 
Table 2. Parameters for the network inversion.

\begin{tabular}{|l|l|}
\hline Input layer neurons & 4 \\
\hline Hidden layer neurons & 30 \\
\hline Output layer neurons & 1 \\
\hline Maximum number of training epochs & 1000 \\
\hline Maximum number of estimation epochs & 1000 \\
\hline Maximum training rate & 0.001 \\
\hline Maximum estimation rate & 0.001 \\
\hline
\end{tabular}

model can predict the force exerted by the MR damper well so that it can be used for direct modeling of MR dampers.

After the forward training phase, the applied current is estimated in the inverse estimating phase so that the MR damper can exert the desirable damping force. The applied current is iteratively updated due to the error between the real force and the estimated one from the neural network. The current is initially set to random values and the learned weights are fixed during the inverse estimation phase. Figure 8(a) shows the comparison of the theoretical current values and the estimated ones by network inversion for the validation data set. Figure 8(b) shows the obtained root-square errors. As is depicted in this figure, only three out of 1419 data used for validation provide an errors greater than $0.6 \mathrm{~A}$. These outlier values correspond to an applied current of $0 \mathrm{~A}$, frequency of excitation of $3 \mathrm{~Hz}$ and low velocities. Note that the validation data have been chosen randomly from the complete set of experimental data and that these validation data have not been used in the phase 1 for training of the neural network. Besides, taking into account that the measured force at low frequencies shows greater variability than at high frequencies (Figure 5), it makes the neural network does not fit properly in these three values corresponding to the same test case. Even so, the value of the root-mean-squared error is $0.09 \mathrm{~A}$ and that the proposed inverse model is capable of commanding a damper to closely track a desired damping force signal. Figure 9 shows the good tracking of the desired force and estimated one in the inverse estimating phase for the proposed method. It is seen that the $95 \%$ of the validation data, data which have not been used to train the neural network, obtain a values of the tracking error below 50 $\mathrm{N}$. It is also observed that for low frequencies of excitation, the proposed model is not able to capture the damping force behaviour at values close the peaks. Nevertheless, for fr qu nci of xcitation of $6 \mathrm{~Hz}$ th propo $\mathrm{d} \bmod 1$ track $\mathrm{v}$ ry $\mathrm{w} 1 \mathrm{ll}$ th $\mathrm{d}$ ir $\mathrm{d}$ on in the whole range of values. This is because the measured force at low frequencies shows greater variability than at high frequencies (Figure 5). Figures 9(b) and 9(d) show the experimental and estimated current against time.

To test the effectiveness of the proposed method, results are compared with the results obtained from an inverse model based on neural networks using supervised learning (Figure 10). The network training was also performed using the Matlab function trainlm. Figure 11(a) shows the comparison of the theoretical current values and the estimated ones by supervised learning for the validation data set. Figure 11(b) show the obtained root-square errors. The value of the root-mean-squared error is $0.20 \mathrm{~A}$ which is higher 


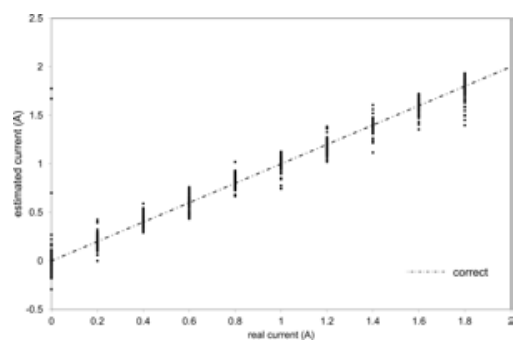

(a)

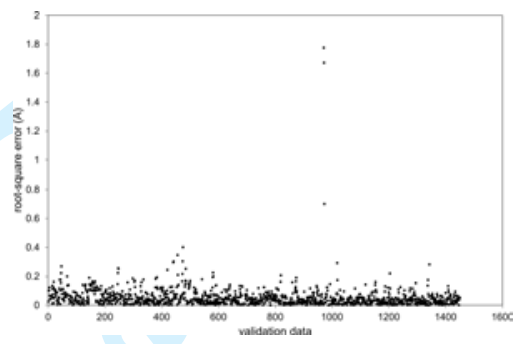

(b)

Figure 8. Comparison between theoretical current values and the estimated ones by the proposed method (network inversion) for the validation data set.

than the proposed method. It is clearly seen that the accuracy of the proposed method based on network inversion is better than the supervised learning method.

\section{Validation and evaluation of MR damper controllers}

In order to analyze the effectiveness of the proposed damper controller, a comparative analysis is established with other damper controllers. Training and validation data are generated by the modified Bouc-Wen damper model which is the most extensive model for describing MR dampers' behaviour. This model, proposed by Spencer et al. (1997), is capable of predicting the response of an MR damper over a wide range of loading under a constant or binary type of voltage. Bouc-Wen model is described by the following equations (see figure 12):

$$
\begin{gathered}
f=c_{1} \cdot \dot{y}+k_{1} \cdot\left(x-x_{0}\right) \\
\dot{z}=-\gamma|\dot{x}-\dot{y}| z|z|^{n-1}-\beta(\dot{x}-\dot{y})|z|^{n}+A(\dot{x}-\dot{y}) \\
\dot{y}=\frac{\alpha z+c_{0} \dot{x}+k_{0}(x-y)}{c_{0}-c_{1}} \\
\alpha=\alpha_{a}+\alpha_{b} u
\end{gathered}
$$




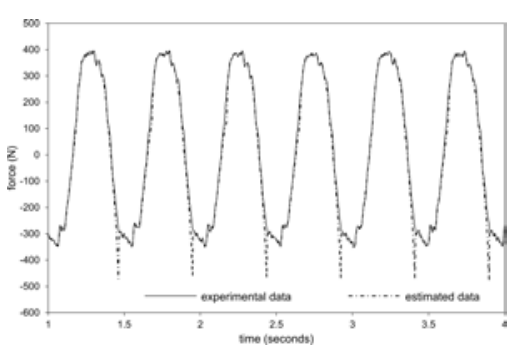

(a)

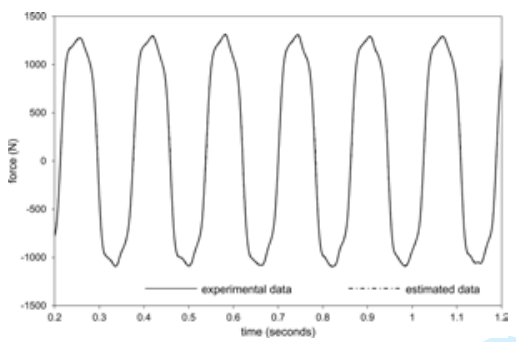

(c)

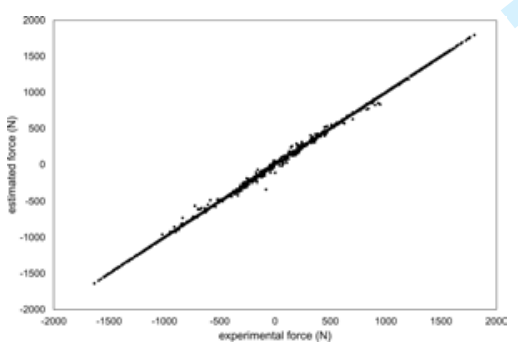

(e)

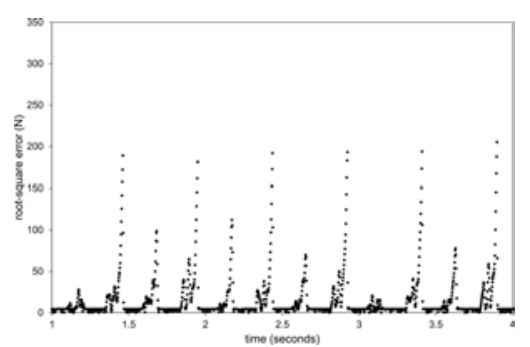

(b)

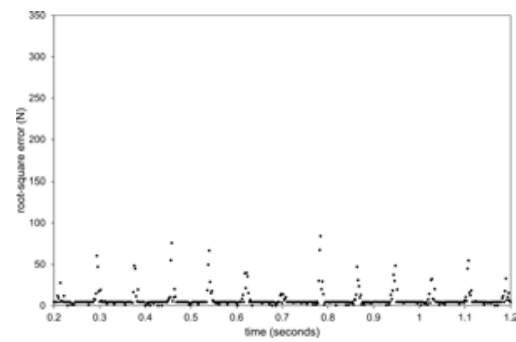

(d)

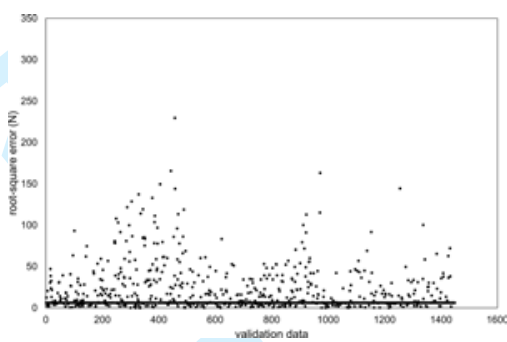

(f)

Figure 9. Comparison between experimental (solid line) and estimated (dashed line) force obtained in the inverse estimating phase phase for a) and b) amplitude of the piston displacement of $10 \mathrm{~mm}$, applied current of $0.2 \mathrm{~A}$ and frequency of excitation of $2 \mathrm{~Hz}, \mathrm{c}$ ) and d) amplitude of the piston displacement of $20 \mathrm{~mm}$, applied current of $1.0 \mathrm{~A}$ and frequency of excitation of $6 \mathrm{~Hz}$, and e) and f) validation data set.

$$
\begin{aligned}
& c_{1}=c_{1 a}+c_{1 b} u \\
& c_{0}=c_{0 a}+c_{0 b} u \\
& \dot{u}=-\eta(u-v)
\end{aligned}
$$




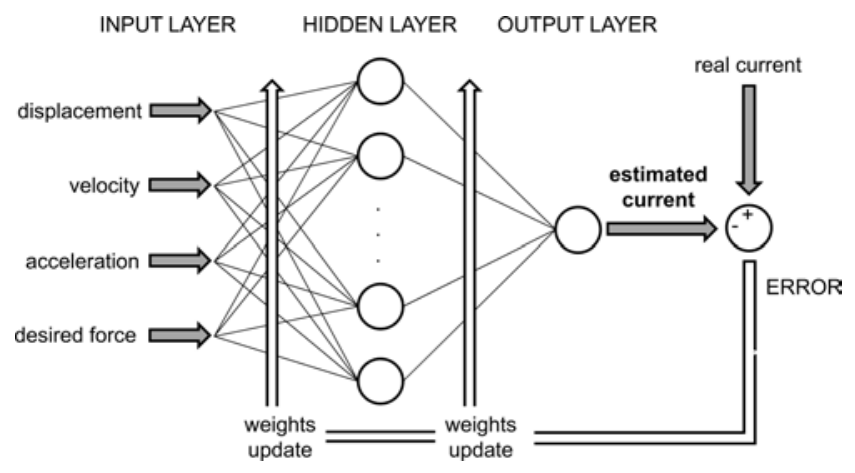

Figure 10. Neural network architecture for inverse modeling of an MR damper by supervised learning.

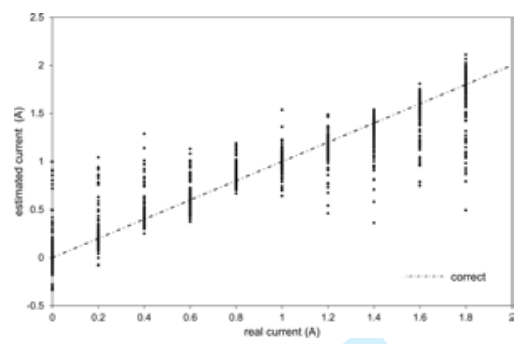

(a)

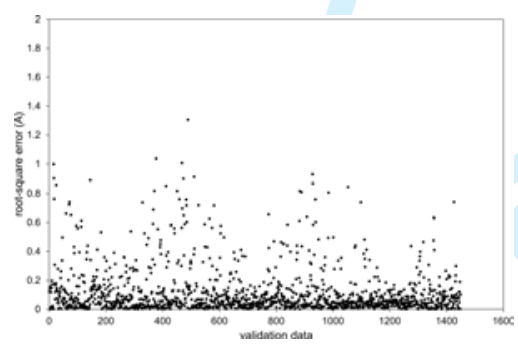

(b)

Figure 11. Comparison between theoretical current values and the estimated ones by supervised learning for the validation data set.

where $\dot{x}$ is the piston velocity, $x$ is the piston displacement, $f$ is the force generated by the MR damper, $\alpha$ is the Bouc-Wen model parameter related to the MR material yield stress, $k_{1}$ is the accumulator stiffness, $c_{1}$ is the dash-pot damping coefficient, $k_{0}$ is present to control the stiffness at large velocities, $c_{0}$ is the viscous damping observed at 
Table 3. Parameters for the Bouc-wen Model of MR damper RD-1005-1 ( Lai and Liao (2002), Wang and Liao (2005)).

\begin{tabular}{|l|l|l|l|}
\hline Parameter & Value & Parameter & Value \\
\hline$c_{0 a}$ & $784 \mathrm{~N} \mathrm{~m}^{-1}$ & $\alpha_{a}$ & $12441 \mathrm{Nm}^{-1}$ \\
\hline$c_{0 b}$ & $1803 \mathrm{NsV}^{-1} \mathrm{~m}^{-1}$ & $\alpha_{b}$ & $38430 \mathrm{NV}^{-1} \mathrm{~m}^{-1}$ \\
\hline$k_{0}$ & $3610 \mathrm{Nm}^{-1}$ & $\gamma$ & $136320 \mathrm{~m}^{-2}$ \\
\hline$c_{1 a}$ & $14649 \mathrm{Nsm}^{-1}$ & $\beta$ & $2059020 \mathrm{~m}^{-2}$ \\
\hline$c_{1 b}$ & $34622 \mathrm{NsV}^{-1} \mathrm{~m}^{-1}$ & $A$ & 58 \\
\hline$k_{1}$ & $840 \mathrm{Nm}^{-1}$ & $n$ & 2 \\
\hline$x_{0}$ & $0.0245 \mathrm{~m}$ & $\eta$ & $190 \mathrm{~s}^{-1}$ \\
\hline
\end{tabular}

larger velocities, $z$ is the hysteretic deformation of the model, $y$ is an internal dynamical variable and $A, \beta$ and $\gamma$ are the Bouc-Wen model parameters. Table 6 shows the values of these parameters corresponding to the RD-1005-1 MR damper, manufactured by Lord Corporation. The 14 parameters have been identified using a constrained nonlinear optimization algorithm from experimental data ( Lai and Liao (2002), Wang and Liao (2005)).

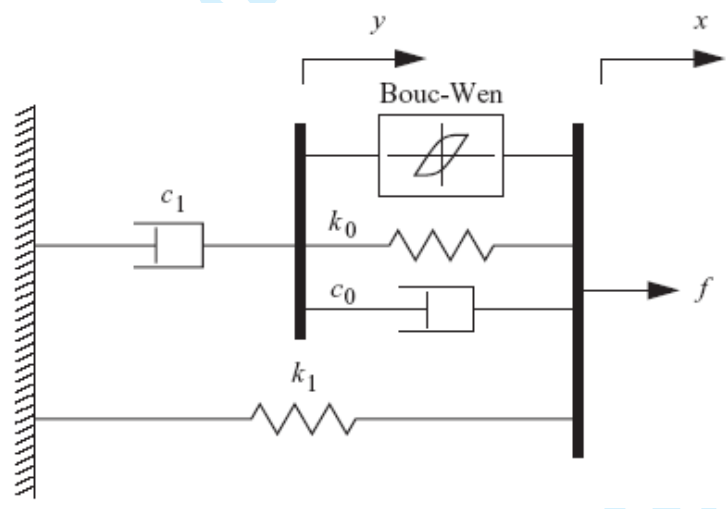

Figure 12. Phenomenological model of MR damper (Spencer et al. (1997))

\section{Data sets for training and validation}

In order to train the proposed NN inverse model, it is necessary to provide an appropriate data sequence. The training data must cover the majority of situations of practical applications in which the MR damper can operate. The data set to be used to train the NN were selected from Wang and Liao (2005) (Table 4). The displacement input is produced using a Gaussian white noise signal and a low pass filter is used to obtain such random signal in the frequency range of $0-3 \mathrm{~Hz}$. The voltage input consists of different signals within different time intervals and the damping force is generated by the modified Bouc-Wen model according to the displacement and voltage inputs. The Bouc-Wen MR 
Table 4. Definition of training data sets ( Wang and Liao (2005)).

\begin{tabular}{|c|c|c|c|}
\hline $\begin{array}{l}\text { Time interval } \\
\text { (s) }\end{array}$ & $\begin{array}{l}\text { Displacement } \\
(\mathrm{cm})\end{array}$ & $\begin{array}{l}\text { Voltage } \\
(\mathrm{V})\end{array}$ & $\begin{array}{l}\text { Force } \\
(\mathrm{N})\end{array}$ \\
\hline $0-60$ & \multirow{5}{*}{$\mathrm{GWN}^{a}{ }^{a}$} & $\mathrm{GWN}^{b}+6$ & \multirow{5}{*}{$\begin{array}{l}\text { Produced by } \\
\text { Bouc-Wen } \\
\text { Model }\end{array}$} \\
\hline $60-70$ & & 12 & \\
\hline $70-80$ & & 6 & \\
\hline $80-90$ & & 0 & \\
\hline $90-100$ & & $6 \sin (4 \pi t+6)$ & \\
\hline
\end{tabular}

${ }^{a}$ Gaussian white noise (frequency: $0-3 \mathrm{~Hz}$; amplitude: $\pm 2.5 \mathrm{~cm}$ )

${ }^{b}$ Gaussian white noise (frequency: 0-4 Hz; amplitude: $\pm 6 \mathrm{~V}$ )

Table 5. Definition of validation data sets ( Wang and Liao (2005)).

\begin{tabular}{|c|c|c|c|c|}
\hline Data set & $\begin{array}{l}\text { Displacement } \\
(\mathrm{cm})\end{array}$ & $\begin{array}{l}\text { Voltage } \\
(\mathrm{V})\end{array}$ & $\begin{array}{l}\text { Force } \\
(\mathrm{N})\end{array}$ & $\begin{array}{l}\text { Time span } \\
\text { (s) }\end{array}$ \\
\hline 1 & $\sin (2 k \pi t)^{a}$ & 1.5 & \multirow{3}{*}{$\begin{array}{l}\text { Produced by } \\
\text { Bouc-Wen } \\
\text { Model }\end{array}$} & 6 \\
\hline 2 & $\mathrm{GWN}^{b}$ & $2+\mathrm{GWN}^{b}$ & & 6 \\
\hline 3 & $\mathrm{GWN}^{b}$ & $1.5+0.75 \sin (2 k \pi t)^{a}$ & & 6 \\
\hline
\end{tabular}

${ }^{a} \mathrm{k}=1,2,3$

${ }^{b}$ Gaussian white noise (frequency: 0-2 Hz; amplitude: $\pm 2 \mathrm{~cm}$ )

damper model was implemented in Simulink. The sampling interval was taken as 0.001 s. In order to validate the accuracy of the proposed inverse model, a validation data sets are defined in Table 5. The obtained results are compared with other damper controllers to prove the effectiveness of the proposed model.

\section{Damper controllers}

Three conventional types of damper controller (Heaviside function, continuous state function and RNN) are considered and evaluated in comparison with the proposed inverse model. The following subsections provide a description of each of damper controller.

Heaviside function damper controller In this method, the applied voltage is determined according to the following equation Dyke et al. (1996):

$$
v=V_{\max } H\left\{\left(f_{d}-f_{a}\right) F_{a}\right\}
$$

where $f_{a}$ is the damper force measures from a force sensor, $f_{d}$ is the desired force, $V_{\max }$ is the maximum voltage to the damper and $H(\cdot)$ is the Heaviside step function:

$$
H(z)= \begin{cases}0 & z<0 \\ 1 & z>0\end{cases}
$$

When the actual force generated by the MR damper is equal to the desired force, the voltage applied to the damper is kept at its current value (Metered et al. (2015).) 
Continuous state function damper controller In this method, the algorithm for selecting the applied voltage is stated as Sims et al. (1999):

$$
v=\left\{\begin{array}{cc}
0, & G\left(f_{d}-B f_{a}\right) \operatorname{sgn}\left(f_{a}\right)<0 \\
G\left(f_{d}-B f_{a}\right) \operatorname{sgn}\left(f_{a}\right), & 0 \leqslant G\left(f_{d}-B f_{a}\right) \operatorname{sgn}\left(f_{a}\right) \leqslant V_{\max } \\
V_{\max }, & G\left(f_{d}-B f_{a}\right) \operatorname{sgn}\left(f_{a}\right)>V_{\max }
\end{array}\right.
$$

where $V_{\max }$ is the maximum voltage applied to the damper. The values of $G$ and $B$ are 0.021 and 1, respectively. These values were selected from Liao and Lai (2002).

RNN damper controller Wang and Liao (2005) and Metered et al. (2015) propose an inverse damper controller based on recurrent neural networks (RNN) which is used to predict the applied voltage that will produce the desired force. In the RNN model, the output of the neural network, the command voltage, is delayed and fed back to its input layer. The input of the NN model is also composed of the time-histories of the displacement and the force output of the MR damper. In this work, the RNN has a single hidden layer with 30 neurons. Figure 13 shows the scheme of the RNN model. The vector of inputs to the net is given by:

$$
\begin{aligned}
& \mathbf{p}(k)=\left[\begin{array}{c}
\mathbf{f}_{d}(k) \\
\mathbf{x}(k) \\
\mathbf{v}(k)
\end{array}\right], \mathbf{f}_{d}(k)=\left[\begin{array}{c}
f_{d}(k) \\
f_{d}(k-1)
\end{array}\right], \mathbf{x}(k)=\left[\begin{array}{c}
x(k) \\
x(k-1)
\end{array}\right], \\
& \mathbf{v}(k)=\left[\begin{array}{llll}
v(k) & v(k-1) & \ldots & v(k-5)
\end{array}\right]
\end{aligned}
$$

and the output of the net is $v(k+1)$.

The Levenberg-Marquardt Backpropagation algorithm is used to learn the weights of the RNN looking for the minimum value of the error. The network training was performed using the Matlab function trainlm.

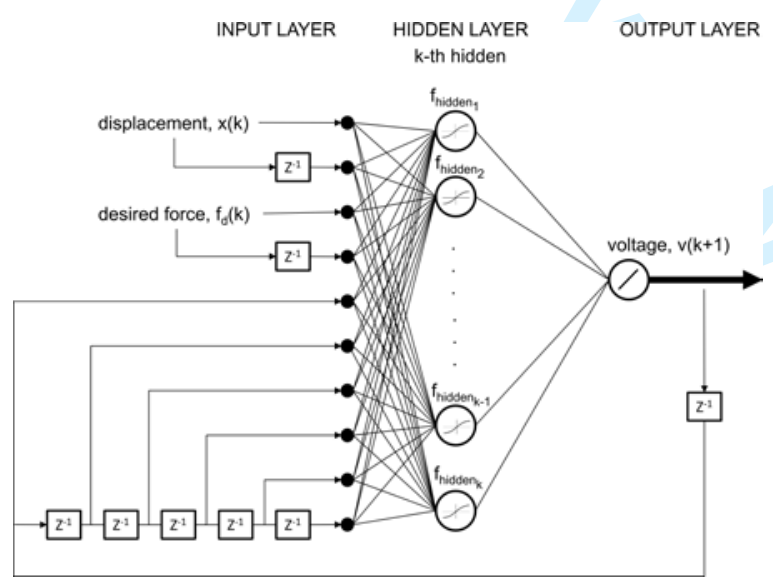

Figure 13. RNN architecture for the inverse dynamic model 
Table 6. Error norms, $E_{t}$, for damper controllers and validation data sets.

\begin{tabular}{|l|l|l|l|l|l|l|l|}
\hline \multirow{2}{*}{} & \multicolumn{6}{|l|}{ Validation data set } \\
\cline { 2 - 8 } & 1 & $\mathrm{k}=2$ & $\mathrm{k}=3$ & & $\mathrm{k}=1$ & $\mathrm{k}=2$ & $\mathrm{k}=3$ \\
\cline { 2 - 8 } & $\mathrm{k}=1$ & $\mathrm{k}$ & & 3 & \multicolumn{3}{l|}{} \\
\hline Heaviside & 0.5622 & 0.5622 & 0.5622 & 0.3936 & 0.4372 & 0.5075 & 0.4523 \\
\hline CS & 0.5588 & 0.5588 & 0.5588 & 0.4067 & 0.4790 & 0.4790 & 0.4912 \\
\hline RNN & 0.0118 & 0.0113 & 0.0118 & 0.0095 & 0.0118 & 0.0108 & 0.0113 \\
\hline Supervised & 0.1951 & 0.1951 & 0.1951 & 0.2124 & 0.4225 & 0.3728 & 0.2475 \\
\hline Proposed & 0.0394 & 0.0394 & 0.0394 & 0.1335 & 0.1217 & 0.1954 & 0.1321 \\
\hline
\end{tabular}

\section{Results and Discussion}

Figures 14, 15 and 16 show a comparison between the predicted and desired values of voltage and force using the proposed NN inverse model and the three conventional types of damper controller for validation set 1 with $k=3$, validation set 2 and validation set 3 with $k=1$, respectively. Results show that the proposed inverse model has a better performance than the heaviside and CS damper controllers. Nevertheless, the RNN damper controller offers a superior tracking than the proposed inverse model, the results obtained with the latter can be considered as adequated. The proposed model successfully tracks the desired damper.

Proof of the effectiveness of the proposed model was performed by means of a quantitative analysis that takes into consideration the error for the different accomplished damper controllers. The following equation has been used to represent the norm error as a function of time (Boada et al. (2011)):

$$
E_{t}=\frac{\varepsilon_{t}}{\sigma_{f}}
$$

where:

$$
\begin{aligned}
\varepsilon_{t}^{2} & =\int_{0}^{T}\left(f_{d}-f_{a}\right)^{2} \\
\sigma_{f}^{2} & =\int_{0}^{T}\left(f_{d}-\mu_{f}\right)^{2}
\end{aligned}
$$

where $f_{d}$ represents the desired force, $f_{a}$ is the estimated force given by the damper controller and $\mu_{f}$ is the mean value of the desired force during the period T.

Table 6 shows the norm error for the different damper controllers. In addition, the results obtained for the damper controller based on supervised learning, which architecture is shown in Figure 10, is also presented. Results reveal that the proposed inverse model is capable of commanding a damper to closely track a desired damping force signal.

\section{Conclusions}

In this paper, a novel inverse MR damper model based on network inversion is proposed. The inverse MR damper model estimates the necessary current which has to be applied 
to the MR damper in order to exert the desired force. The network inversion implies two phases. In both phases, a MLP neural network is used. The MLP neural network is able to solve both the direct and the inverse MR damper modeling even though the MR dampers exhibit a nonlinear and hysteretic response. The former of the two phases, called inverse estimation phase, employs off-line learning. The network is trained for adjusting the weight values so that is approximated the forward mapping. The latter, called inverse estimation phase, employs on-line learning. In this phase, the current is estimated from the neural network model learned in the previous phase. The neural network only requires four data sets for the forward training phase and three ones for the inverse estimating phase. These data can be easily measured using sensors (displacement of the MR damper piston and the force exerted by the MR damper) or estimated using Kalman Filter (damper velocity and acceleration). Results show the effectiveness of the network inversion for inverse modeling of an MR damper and they reveal that the proposed inverse model is capable of commanding a damper to closely track a desired damping force signal.

\section{Funding}

This work was supported by the funds provided by the Spanish Government through the CICYT projects TRA2008-05373/AUT and TRA2011-28548-C02-01.

\section{References}

Ali SF and Ramaswamy A (2009) Testing and modeling of MR damper and its application to SDOF systems using integral backstepping technique. Journal of Dynamic Systems, Measurement, and Control 131(2): 021009-021009.

Belanger PR (1992) Estimation of angular velocity and acceleration from shaft encoder measurements. In: Robotics and Automation, 1992. Proceedings., 1992 IEEE International Conference on, volume 1. pp. 585-592.

Bhowmik S (2011) Modelling and control of magnetorheological damper: real-time implementation and experimental verification. Report (DCAMM).: S DTU Mekanik and Danish Center for Applied Mathematics and Mechanics. isbn: 9788790416706.

Boada MJL, Calvo JA, Boada BL and Diaz V (2011) Modeling of a magnetorheological damper by recursive lazy learning. International Journal of Non-Linear Mechanics 46(3): 479-485.

Chang C and Zhou L (2002) Neural network emulation of inverse dynamics for a magnetorheological damper. Journal of Structural Engineering 128(2): 231-239.

Choi S, SL and Park Y (2001) A hysteresis model for the field-dependent damping force of a magnetorheological damper. Journal of Sound and Vibration 245(2): 375-383.

Choi SB and Han YM (2005) Hysteretic behavior of a magnetorheological fluid: experimental identification. Acta Mechanica 180(1): 37-47.

$\mathrm{Du}$ H, Lam J and Zhang N (2006) Modelling of a magneto-rheological damper by evolving radial basis function networks. Engineering Applications of Artificial Intelligence 19(8): 869-881.

Dyke SJ, Jr BFS, Sain MK and Carlson JD (1996) Modeling and control of magnetorheological dampers for seismic response reduction. Smart Materials and Structures 5(5): 565-575. 
Ekkachai K,Tungpimolrut K and Nilkhamhang I (2013) Force control of a magnetorheological damper using an elementary hysteresis model-based feedforward neural network. Smart Materials and Structures 22(11): 115030.

El-Khoury O, Kim C, Shafieezadeh A, Hur JE and Heo GH (2016) Mitigation of the seismic response of multi-span bridges using MR dampers: Experimental study of a new SMC-based controller. Journal of Vibration and Control .

Gamota D and Filisko F (1991) Dynamic mechanical studies of electrorheological materials: Moderate frequencies. Journal of Rheology 35: 399-425.

Giuclea M, Sireteanu T, Stancioiu D and Stammers CW (2004) Model parameter identification for vehicle vibration control with magnetorheological dampers using computational intelligence methods. Proceedings of the Institution of Mechanical Engineers, Part I: Journal of Systems and Control Engineering 218(7): 569-581.

Jensen CA, Reed RD, Marks RJ, El-Sharkawi MA, Jung JB, Miyamoto RT, Anderson GM and Eggen CJ (1999) Inversion of feedforward neural networks: algorithms and applications. Proceedings of the IEEE 87(9): 1536-1549.

Kwok NM, Ha QP, Nguyen MT, Li J and Samali B (2007) Bouc-Wen model parameter identification for a MR fluid damper using computationally efficient GA. ISA transactions 46(2): 167-179.

Li Z, Zheng J, Koo JH and Wang J (2013) An improved polynomial dynamic model of a magnetorheological fluid damper under impact loadings. In: Proc. SPIE 8688, Active and Passive Smart Structures and Integrated Systems, volume 8688.

Lai CY and Liao WH (2002) Vibration Control of a Suspension System via a Magnetorheological Fluid Damper. Journal of Vibration and Control 8(4): 527-547.

Liao WH and Lai CY (2002) Harmonic analysis of a magnetorheological damper for vibration control. Smart Materials and Structures 11(2): 288-296.

Linden A and Kindermann J (1989) Inversion of multilayer nets. In: Neural Networks, 1989. IJCNN., International Joint Conference on. pp. 425-430 vol.2.

Metered H, Bonello P and Oyadiji SO (2010) The experimental identification of magnetorheological dampers and evaluation of their controllers. Mechanical Systems and Signal Processing 24(4): 976-994.

Metered H, Bonello P and Oyadiji S (2015) Nonparametric identification modeling of magnetorheological damper using chebyshev polynomials fits. SAE International Journal of Passenger Cars - Mechanical Systems 2(1): 1125-1135.

Nehl TW, Betts JA and Mihalko LS (1995) An integrated relative velocity sensor for real time damping applications. In: Industry Applications Conference, 1995. Thirtieth IAS Annual Meeting, IAS '95., Conference Record of the 1995 IEEE, volume 1. pp. 484-491.

Ogawa T (2016) Neural network inversion for multilayer quaternion neural network. Computer Technology and Application 7: 73-82.

Ogawa T and Kanada H (2010) Solution for ill-posed inverse kinematics of robot arm by network inversion. Journal of Robotics 2010: 1-9.

Ogawa T, Kosugi Y and Kanada H (1998) Neural network based solution to inverse problems. In: Neural Networks Proceedings, 1998. IEEE World Congress on Computational Intelligence. 
The 1998 IEEE International Joint Conference on, volume 3. pp. 2471-2476 vol.3.

Owaga T (2009) Complex-Valued Neural Network and Inverse Problems, chapter 2. ComplexValued Neural Networks: Utilizing High-Dimensional Parameters. IGI Global, pp. 27-55.

Phu DX, Choi SM and Choi SB (2016) A new adaptive hybrid controller for vibration control of a vehicle seat suspension featuring MR damper. Journal of Vibration and Control .

Puglisi LJ, Saltaren RJ and Garcia-Cena CE (2015) On the velocity and acceleration estimation from discrete time-position signal of linear encoders. Journal of Control Engineering and Applied Informatics 17(3): 30-40.

Saad EW and Wunsch DC (2007) Neural network explanation using inversion. Neural Networks 20(1): 78-93.

Sims ND, Stanway R, Peel DJ, Bullough WA and Johnson AR (1999) Controllable viscous damping: an experimental study of an electrorheological long-stroke damper under proportional feedback control. Smart Materials and Structures 8(5): 601-615.

Smyth AW, Masri SF, Kosmatopoulos EB, Chassiakos AG and Caughey TK (2002) Development of adaptive modeling techniques for non-linear hysteretic systems. International Journal of Non-Linear Mechanics 37(8): 1435-1451.

Spencer BF, Dyke SJ, Sain MK and Carlson JD (1997) Phenomenological Model for Magnetorheological Dampers. Journal of Engineering Mechanics 123(3): 230-238.

Stanway R, Sproston JL and Stevens NG (1987) Non-linear modeling of an electrorheological vibration damper. Journal of Electrostatics 20: 167-184.

Tsang HH, Su RKL and Chandler AM (2006) Simplified inverse dynamics models for MR fluid dampers. Engineering Structures 28(3): 327-341.

Tudon-Martinez JC, Lozoya-Santos JJ, Morales-Menendez R and Ramirez-Mendoza RA (2012) An experimental artificial-neural-network-based modeling of magneto-rheological fluid dampers. Smart Materials and Structures 21(8): 1-15.

Tudon-Martinez JC and Morales-Menendez R (2015) Nonparametric Modeling of an Automotive Damper Based on ANN: Effect in the Control of a Semi-active Suspension. Computational Intelligence: International Joint Conference, IJCCI 2012 Barcelona, Spain, October 5-7, 2012 Revised Selected Papers. Springer International Publishing. Editor: Madani, Kurosh and Correia, Dourado A, Agostinho R and Joaquim F. Address: Cham. 295-309

Wang DH and Liao WH (2005) Modeling and control of magnetorheological fluid dampers using neural networks. Smart Materials and Structures 14(1): 111-126.

Wang W and Song Y (2012) Nonlinear vibration semi-active control of automotive steering using magnetorheological damper.

Wereley N, Pang L and Kamath G (1998) Idealized hysteresis modeling of electrorheological and magnetorheological dampers. Journal of Intelligent Material Systems and Structures 9(8): 642-649.

Pin-Qi Xia (2003) An inverse model of MR damper using optimal neural network and system identification. Journal of Sound and Vibration 266(5): 1009-1023.

Xiaomin X, Qing S, Ling Z and Bin Z (2009) Parameter estimation and its sensitivity analysis of the MR damper hysteresis model using a modified genetic algorithm. Journal of Intelligent Material Systems and Structures. 
Zapateiro M, Pozo F, Karimi HR and Luo N (2012) Semiactive control methodologies for suspension control with magnetorheological dampers. IEEE/ASME Transactions on Mechatronics 17(2): 370-380.

Zareh SH, Matbou F and Khayyat AAA (2014) Experiment of new laboratory prototyped magnetorheological dampers on a light commercial vehicle using neuro-fuzzy algorithm. Journal of Vibration and Control .

Zong LH, Gong XL, Guo CY and Xuan SH (2012) Inverse neuro-fuzzy MR damper model and its application in vibration control of vehicle suspension system. Vehicle System Dynamics 50(7): 1025-1041. 


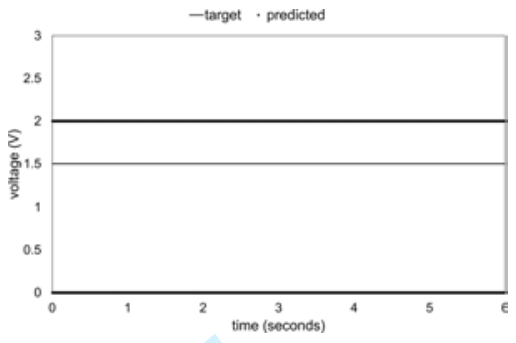

(a)

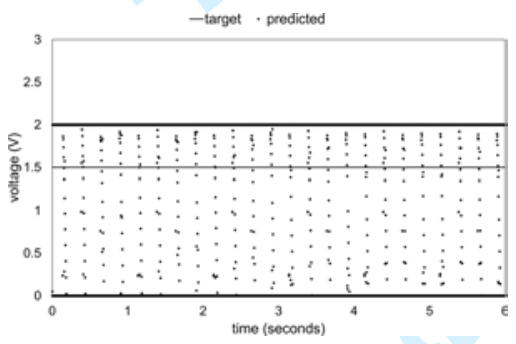

(c)

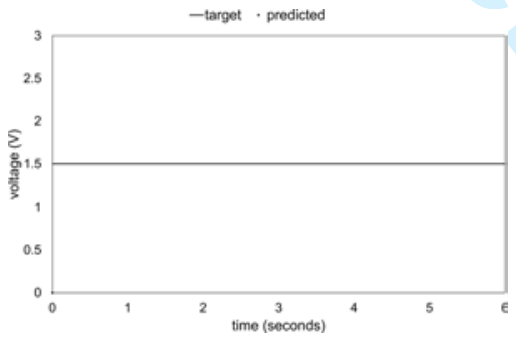

(e)

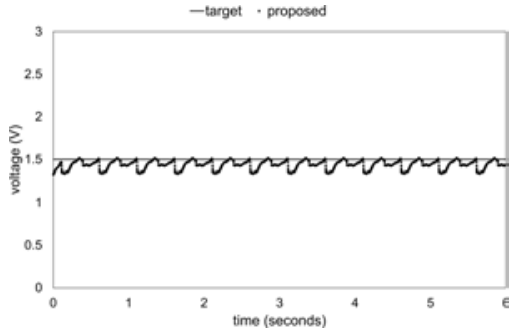

(g)

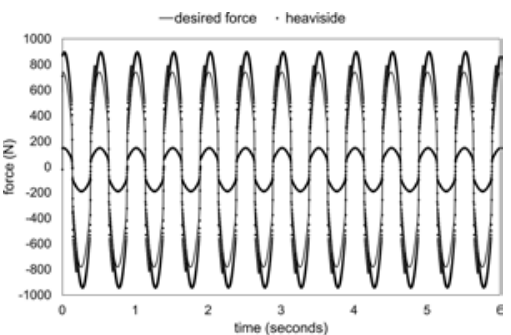

(b)

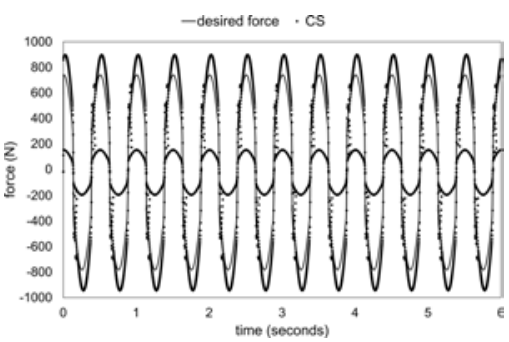

(d)

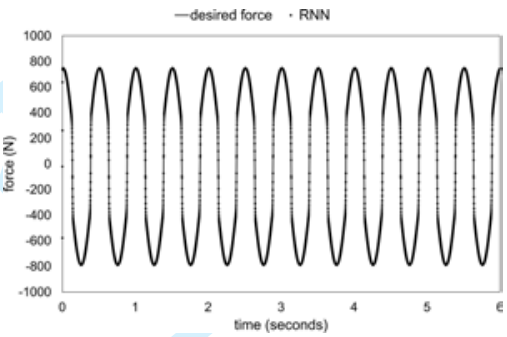

(f)

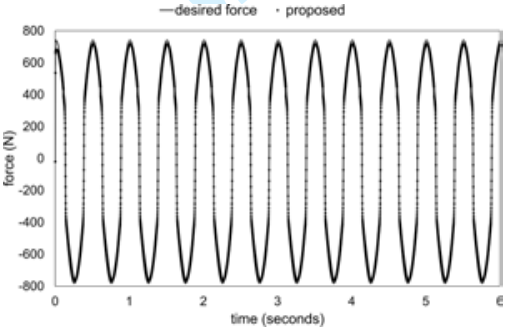

(h)

Figure 14. Comparison between conventional damper controller ((a-b) Heaviside, (c-d) CS, (e-f) RNN, (g-h) with the proposed damper controller) for validation data set $1, \mathrm{k}=3$. 


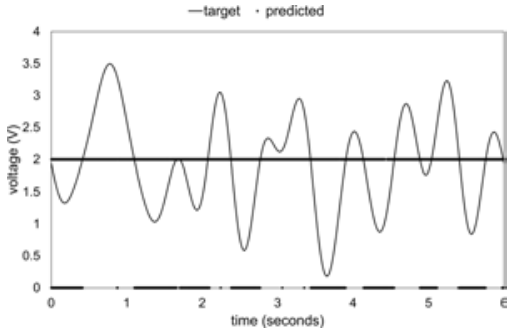

(a)

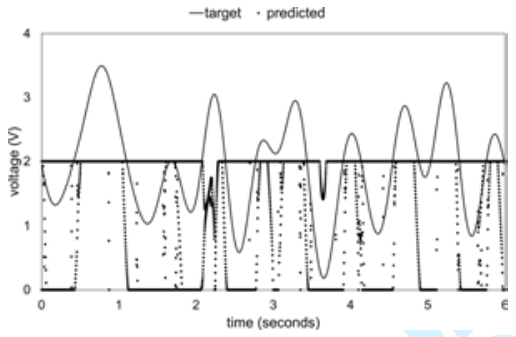

(c)

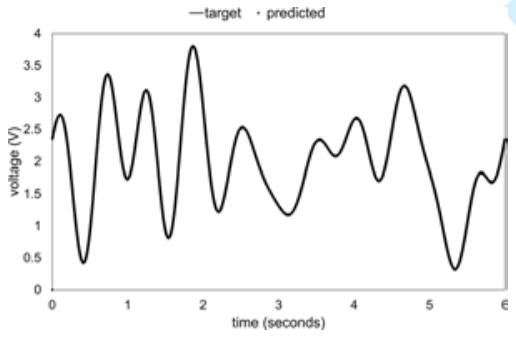

(e)

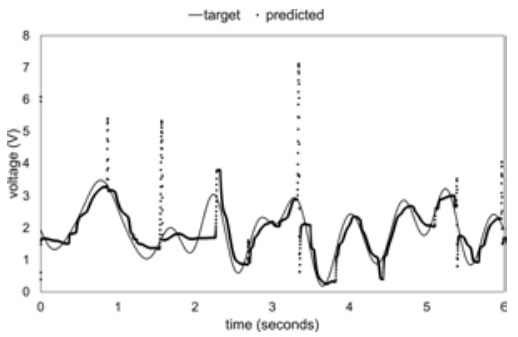

(g)

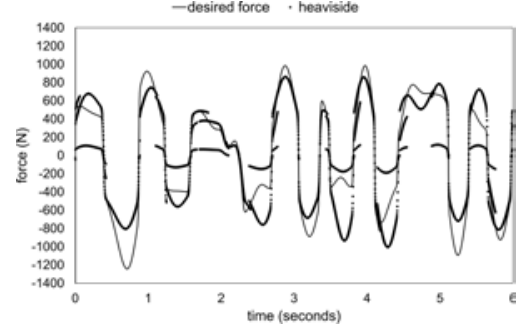

(b)

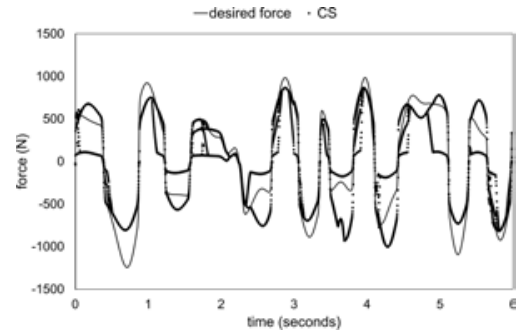

(d)

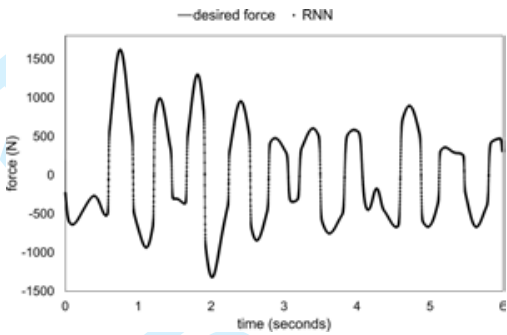

(f)

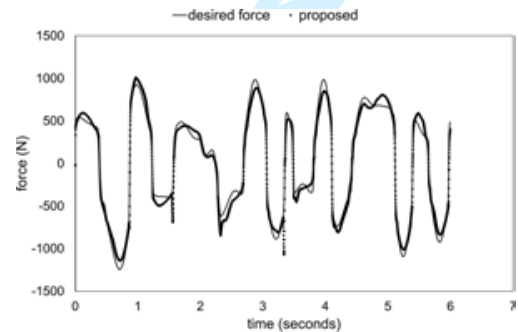

(h)

Figure 15. Comparison between conventional damper controller ((a-b) Heaviside, (c-d) CS, (e-f) RNN, (g-h) with the proposed damper controller) for validation data set 2. 


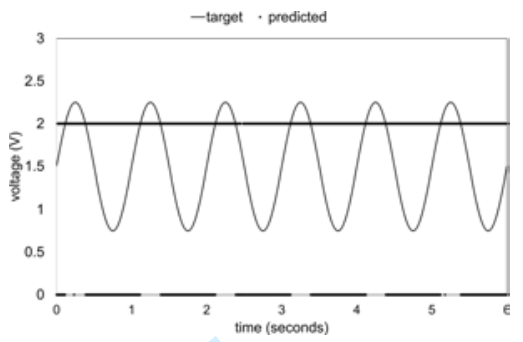

(a) 